Cilt/Volume:13 Sayı/Issue:3 Aralık/December 2021 Özel Sayı / Special Issue

\title{
WE43 Magnezyum Alaşımlarının RF Sıçratma Yöntemi ile Tantal-Oksit Kaplanması ve Karakterizasyonu
}

\section{Tantalum-Oxide Coating and Characterization of WE43 Magnesium Alloys by RF Sputtering Method}

\author{
Canser Gül ${ }^{1}$ iD, Sevda Albayrak ${ }^{2}$ iD, Hanifi Çinici ${ }^{2}$ iD \\ ${ }^{1}$ Manisa Celal Bayar Üniversitesi, Mühendislik Fakültesi, Metalurji ve Malzeme Mühendisliği, Manisa, Türkiye \\ ${ }^{2}$ Gazi Üniversitesi, Teknoloji Fakültesi, Metalurji ve Malzeme Mühendisliği, Ankara, Türkiye
}

Başvuru/Received: 07/10/2021

Kabul / Accepted: 25/12/2021

Çevrimiçi Basım / Published Online: 31/12/2021

Son Versiyon/Final Version: 31/12/2021

\section{Öz}

Magnezyum alaşımları yüksek özgül dayanımları nedeni ile otomotiv ve havacılık sektörlerinde sıklıkla kullanılan alaşımlardır. Alaşımların aşınma ve korozyon dayanımlarını arttırmaya yönelik yoğunlaşan çeşitli çalışmalar sürdürülmektedir. Yapılan çalışma, WE43 magnezyum alaşımın tantal-oksit ile kaplanması ve karakterizasyonunu içermektedir. WE43 magnezyum alaşımına RF sıçratma yöntemi ile tantal-oksit kaplamalar uygulanmıştır. Kaplama işlemi öncesi yüzeylere uygulanan asit aşındırma işleminin etkisini gözlemleyebilmek amacıyla, $\mathrm{H}_{2} \mathrm{SO}_{4}$ ve $\mathrm{HCl}$ asit karışımları kullanılmış ve numuneler asit ile $25,45,65$ ve $85^{\circ} \mathrm{C}^{\prime}$ de parlatma sonrası asit aşındırma işlemine tabi tutulmuştur. Uygulanan asit aşındırma işlemlerinin kaplanmış yüzeylere etkileri çalışma kapsamında incelenmiş̧ir. Uygulanan işlemlerin kaplama öncesi yüzey morfolojisine, yüzey ile kaplama tabakası arasında oluşan metalürjik bağa ve kaplama sonrası yüzey özelliklerine olan etkileri taramalı elektron mikroskobu, enerji dağılım spektroskopisi, Xışını taraması ve kesitten alınan kaplama kalınlık ölçümleri ile incelenmiştir. Çalışma sonucunda, kaplama öncesi yüzeylerde farklılıklar olduğu, çatlaklı ve aşınmış alanlar gözlemlendiği ve buna rağmen yüzeylerde çatlaksız/gözeneksiz, sürekliliği olan ve homojen kaplama tabakaları elde edildiği tespit edilmiştir. Uygulanan yüzey işlemleri yüzey kimyasında ve morfolojisinde çeşitli

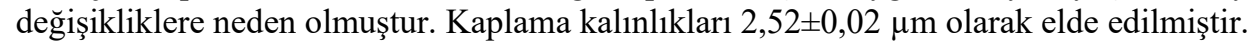

\section{Anahtar Kelimeler}

"Magnezyum, Kaplama, Tantal-oksit, Karakterizasyon"

\begin{abstract}
Magnesium alloys are frequently used in the automotive and aerospace industries due to their high specific strength. Various studies are carried out to increase the wear and corrosion resistance of alloys. The study includes the coating and characterization of WE43 magnesium alloys, with tantalum-oxide. Tantalum-oxide coatings were applied to WE43 magnesium alloy by RF sputtering method. In order to observe the effect of acid etching applied to the surfaces before the coating process, $\mathrm{H}_{2} \mathrm{SO}_{4}$ and $\mathrm{HCl}$ acid mixtures were used and the samples were subjected to acid etching after polishing at $25,45,65$ and $85{ }^{\circ} \mathrm{C}$, with in contact with the acid. The effects of the applied acid etching processes on the coated surfaces were investigated within the study. The effects of the applied processes on surface morphology before coating, the metallurgical bond formed between the surface and coating layer and the surface properties after coating were investigated by scanning electron microscopy, energy distribution spectroscopy, X-ray scanning and coating thickness measurements taken from the cross section. As a result, it was determined there were differences in the surfaces before the coating, cracked and worn areas were observed, and nevertheless, crack-free/non-porous, continuous and homogeneous coating layers were obtained on the surfaces. The applied surface treatments caused changes in the surface chemistry and morphology. Coating thicknesses were obtained as $2.52 \pm 0.02 \mu \mathrm{m}$.
\end{abstract}

\section{Key Words}

"Magnesium, Coating, Tantalum-oxide, Characterisation" 


\section{Giriş}

En hafif yapı malzemelerinden biri olan magnezyum (yaklaşık $1,7 \mathrm{~g} / \mathrm{cm}^{3}$ ), alüminyumun (yaklaşık 2,7 g/ $\mathrm{cm}^{3}$ ) 2/3'ü kadardır. WE43 $\mathrm{Mg}$ alaşımı, özellikle $250^{\circ} \mathrm{C}$ 'ye kadar kullanılabilen yüksek mukavemetli Mg alaşımları grubundadır (Ignat vd., 2004; Kubasek vd., 2019). İtriyum ( $\mathrm{Y}$, ağ. \%3,42) ile Neodimyum (Nd, ağ. \%2,42) nadir toprak elementlerini bünyesinde barındırmakta olup (Zucchi vd., 2006), mukavemetleri 350-400 MPa kadardır (Antion vd., 2003). Bu alaşımın en önemli avantajı düşük yoğunluğuna rağmen üstün performans sergilemesidir. Bu özelliği sayesinde havacılık ve uzay araçlarında, otomotiv sektöründe tercih edilmektedir. Ayrıca bu sektörlerin yanı sıra mükemmel biyouyumlulukları ve mekanik uyumlulukları nedeni ile bozunabilir vidalar, plakalar ve hatta stentler olarak da biyomalzeme alanında kullanımı mevcuttur ve yapısında bulunan Y ve Nd elementlerinin sağladığı koruyucu tabaka sayesinde diğer Mg alaşımlarına kıyasla çok daha iyi bir korozyon dayanımı sergiler (Kubasek vd., 2019; Cao vd., 2016; Byun vd., 2020). Her ne kadar diğer $\mathrm{Mg}$ alaşımlarına göre daha iyi korozyon dayanımına sahip olsa da $\mathrm{Cl}^{-}$ve $\mathrm{F}^{-}$iyonları içeren ortamlardaki uygulamalar için pek tercih edilmemektedir. Bu ortamlarda ortaya çıkan korozyon, malzemenin bozunarak işlevini yitirmesine sebep olmaktadır (Pereira vd., 2021). Mg, oksidasyon işlemi sırasında yüzeyde film oluşturacak olsa da filmin ince olması ve kompakt olmaması nedeniyle korozyon direncinin geliştirilmesi son derece sınılıdır. Ancak özellikle kaplama, alaşımlama ve ısıl işlem ile Mg alaşımlı ürünlerin korozyon direncini arttırmak mümkündür (Hänzi vd., 2009; Yang vd., 2020; Höhlinger vd., 2017). Tantal elementi ise biyomedikal, optik, kimya, endüstrisi uygulamalarda korozyon dayanımı sağlamak için kullanılan, yüksek korozyon dayanımına sahip bir elementtir. (Gül vd., 2020; Chen vd., 2019; Chang vd., 2014). $\alpha$-Mg matrisi (anot) ve ikincil fazlar (katotlar) arasında oluşan farklı elektrot potansiyelleri nedeniyle, $\mathrm{Mg}$ alaşımları galvanik korozyona karşı oldukça hassastır, bu nedenle $\mathrm{Mg}$ alaşımlarında yerel korozyon sıklıkla gözlenir ve bu da Mg alaşımlarının korozyon direncinin düşmesine neden olur (Cao vd., 2016).

Yapılan çalışmanın amacı magnezyum ve alaşımları üzerinde çatlaksız ve homojen bir kaplama eldesinin sağlandığı kaplamalar oluşturmak ve birçok avantaja sahip bu alaşım gruplarının yüzey özelliklerinin geliştirilerek uygulamalarda kullanılabilirliğinin arttırılmasıdır. $\mathrm{Bu}$ amaçla seyreltilmiş $\mathrm{H}_{2} \mathrm{SO}_{4} \mathrm{ve} \mathrm{HCl}$ asit karışımı ile farklı sıcaklıklarda uygulanan yüzey aşındırma işlemi sonrası $\mathrm{RF}$ sıçratma yöntemi ile tantal oksit kaplanan yapıların morfolojisine olan etkisi incelenmiştir. $25,45,65$ ve $85^{\circ} \mathrm{C}$ sıcaklıklarda 5 'er dakika süre ile bekletilen WE43 Mg alaşımları kaplanmış ve karakterize edilmiştir. İncelemeler, yüzeyden ve kesitten yapılan taramalı elektron mikroskop görüntülemelerini, elektron dağılım spektrum ölçümlerini ve X-ışını kırınımı taramalarını kapsamaktadır.

\section{Malzeme ve Metot}

WE43 alaşımı (Kimyasal Bileşim \% ağ.; 2.5-3.5\% Nd, 1.4-4.2\% Y, <1\% (Fe, Al, Zn, Ni, Mn, Cu, Zr ve kalan Mg) 50mm uzunluk ve $20 \mathrm{~mm}$ çapında silindirik ekstrüze çubuk şeklinde temin edilmiştir. Alaşım çubuk $4 \mathrm{~mm}$ kalınlıklarda dilimlenmiştir. Numunelerin enine kesitleri 2500 gride kadar $\mathrm{SiC}$ zımpara kâğıtları ile zımparalanmış ve sonrasında yağ bazlı parlatma solüsyonları ile parlatılmıştır. Parlatma işlemi sonrası uygulanan asit ile aşındırma işlemlerinde $\mathrm{H}_{2} \mathrm{SO}_{4}$ ve $\mathrm{HCl}$ asit karışımı kullanılarak $25,45,65$ ve $85{ }^{\circ} \mathrm{C}$ sıcaklıklarda 5'er dakika bekletilmesi suretiyle yüzeylerin aktif hale getirilmesi sağlanmıştır. Daha önce yapılan çalışmada da yüzeylerin asit ile muamele edilmesinin yüzey morfolojilerine olumlu etkileri tespit edildiğinden bu çalışma için de bu prosedürler uygulanmıştır (Gül ve Albayrak, 2021). Kaplama öncesi yüzey pürüzlülükleri Manisa Celal Bayar Üniversitesi Metalurji ve Malzeme Mühendisliği Bölümüne ait Surftest SJ 410 yüzey profilometresi ile ölçülmüş̧ür.

Kaplama işlemleri Ankara Yıldırım Beyazıt Üniversitesi Merkez Laboratuvarında bulunan OptoSense KYKY RF sıçratma cihazında 1 mm kalılıkta $\mathrm{Cu}$ altlıklı \%99,9 saflıkta $\mathrm{Ta}_{2} \mathrm{O}_{5}$ hedef kullanılarak gerçekleştirilmiştir. Kaplamalar $10 \mathrm{~cm}$ mesafeden $10^{-3} \mathrm{~Pa}$ basınç kullanılarak 20 SCCM Ar gaz akışı altında gerçekleştirilmiştir. 200W güç kullanılmış ve kaplama süresi 90 dakika olacak şekilde ayarlanmıştır.

Numunelerin yüzeylerinin morfolojik incelemelerinde, Manisa Celal Bayar Üniversitesi Merkez Laboratuvarı DEFAM'da bulunan Zeiss Marka Gemini Sigma 300VP Modelli taramalı elektron mikroskobu (SEM) ve Gazi Üniversitesi Metalurji ve Malzeme Mühendisliğinde bulunan Sigma JEOL JSM 6060 LV Modelli taramalı elektron mikroskobu (SEM) kullanılmıştır. Görüntüler 5-10 kV hızlandırma gerilimleri kullanılılarak çeşitli büyütmelerde alınmıştır. Kaplama kalınlık ölçümleri $5 \mathrm{kV}$ hızlandırma gerilimi ile 2500X büyütme kullanılarak, kırık kesitten alınmıştır. Kaplama sonrası alınan EDS spektrumu yüzeyden genel olarak alınmış olup 500X büyütmede $15 \mathrm{kV}$ voltaj kullanılmıştır.

Çalışma kapsamında, Gazi Üniversitesi Metalurji ve Malzeme Mühendisliği XRD Laboratuvarında Bruker D8 marka ve modelli XIşını Kırınımı (XRD) cihazı kullanılarak saniyede $0,15^{\circ}$ derece tarama hızında $\mathrm{CuK} \boldsymbol{\alpha}(\boldsymbol{\lambda}=1,5418 \AA$ ) ışını ile, $40 \mathrm{~mA}$ akım ve $40 \mathrm{~V}$ voltaj kullanılarak $10-90^{\circ} 2 \theta$ arasında ölçümler gerçekleştirilmiştir. XRD analizi sonucu elde edilen karakteristik pikler analiz edilerek oluşan fazlar tespit edilmiştir.

\section{Bulgular}

Kaplama işlemi öncesi farklı sıcaklıklarda asit aşındırma işlemi sonrası alınan yüzey pürüzlülük grafikleri Şekil 1'de yüzey SEM görüntüleri ise Şekil 2'de verilmiştir. Yüzeyde asit aşındırma işlemi sonucunda meydana gelen bazı çatlaklar gözlemlenmiştir. Yüzeyin pürüzlendirilmesi ve kaplamaların daha iyi tutunmasını sağlayabilmek amaçları ile gerçekleştirilen asit içinde bekletme işlemi 
yüzeylerde morfolojik bazı farklılıklara neden olmakta olduğu bilinmektedir (Almeida, 2001). Şekil 1 ve 2'de de net bir şekilde asit işlem sıcaklığının artması sonucu daha pürüzlü bir yüzey elde edildiği görülmektedir.

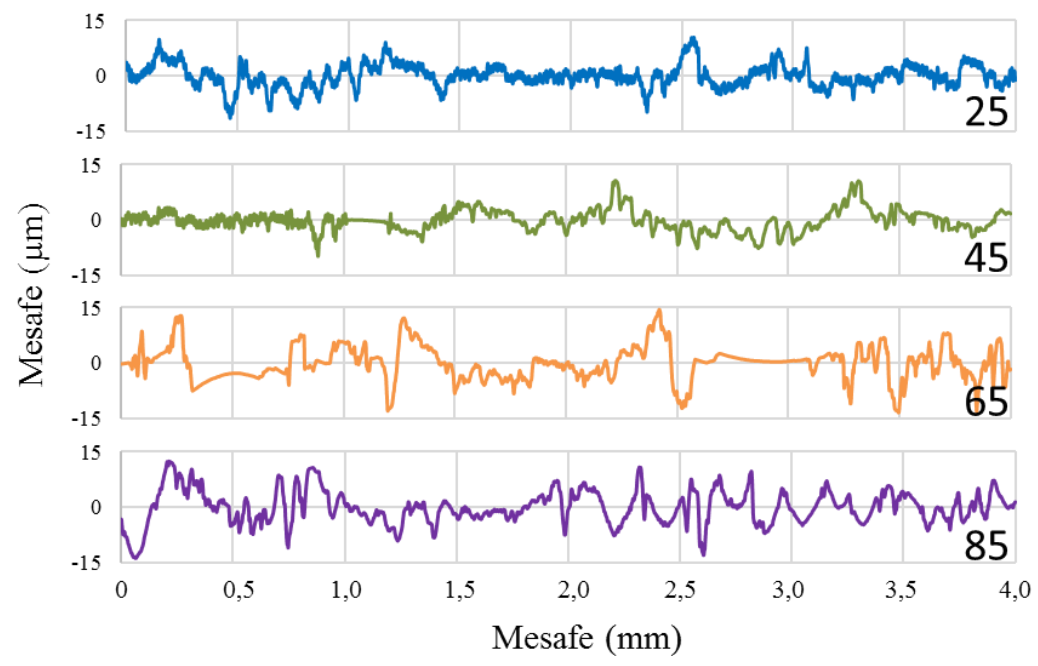

Şekil 1. Kaplama öncesi asitle muamele edilen yüzeylerin pürüzlülük grafikleri.

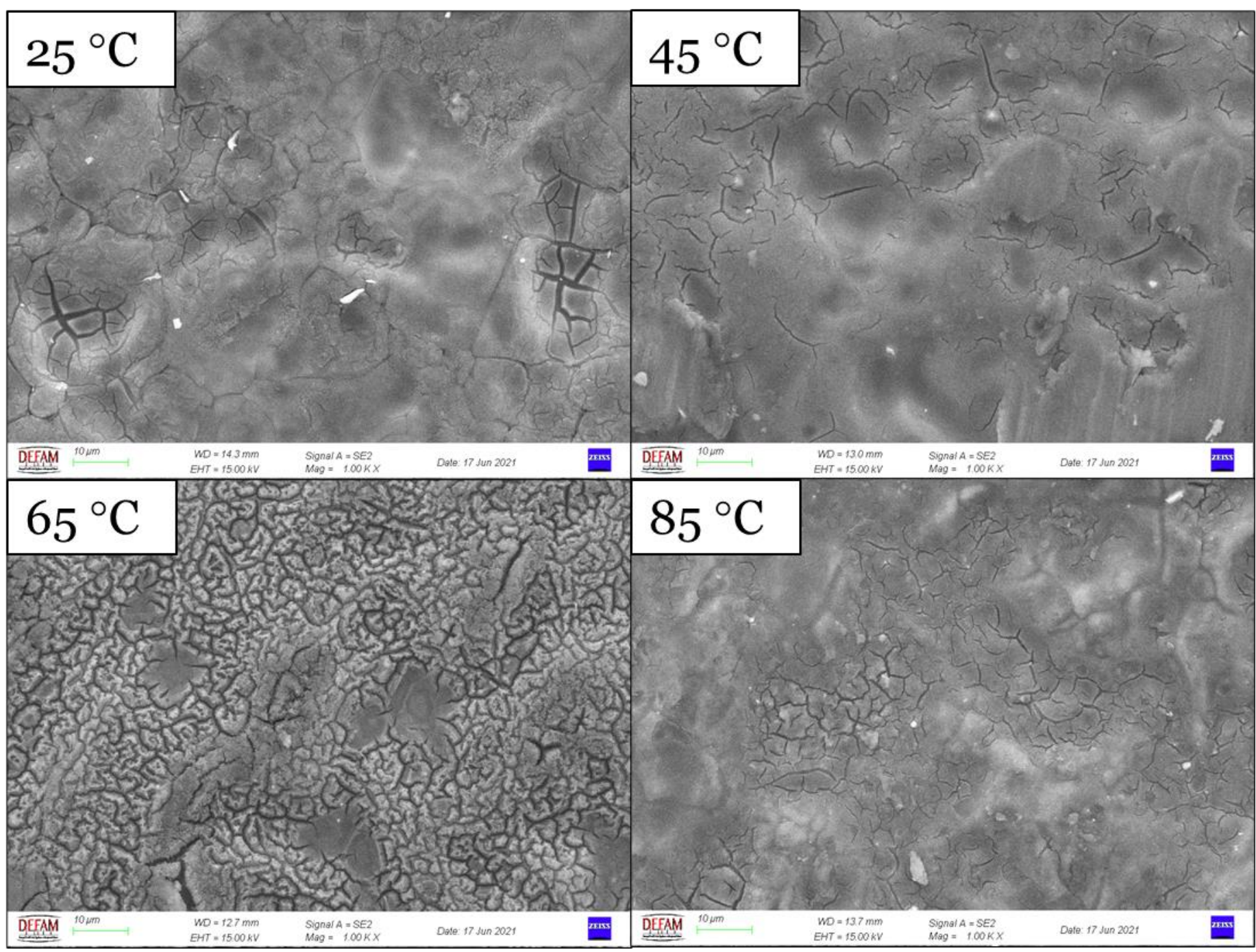

Şekil 2. Kaplama işlemi öncesi $25,45,65$ ve $85^{\circ} \mathrm{C}$ sıcaklıklarda asit aşındırma işlemi sonrası yüzeylerin SEM görüntüleri (1000X). 
Farklı sıcaklıklarda asit ile muamele edilen yüzeylerin kaplama işlemi sonrası alınan yüzey SEM görüntüleri Şekil 3'te görülmektedir. Görüntüler incelendiğinde çatlaklı yapılara rastlanmadığı, boşluk ve gözenek içermeyen bir kaplama eldesinin söz konusu olduğu gözlemlenmiştir. Asit aşındırma işlemi sonrası yüzeylerde gözlemlenen çatlaklı yapılar kaybolmuş ve yüzeyde çatlak gözlemlenmemiştir. Numune yüzeylerindeki kaplama homojenliğinin artan asit işlem sıcaklı̆̆ı ile arttığı ve daha düzgün bir kaplama elde edildiği, bunun sebebinin de yüzey pürüzlendirme işleminin atomik boyutta kaplama malzemesinin yüzeyde çekirdeklenmesini ve tutunmasını kolaylaştırması ile alakalı olduğu düşünülmektedir.

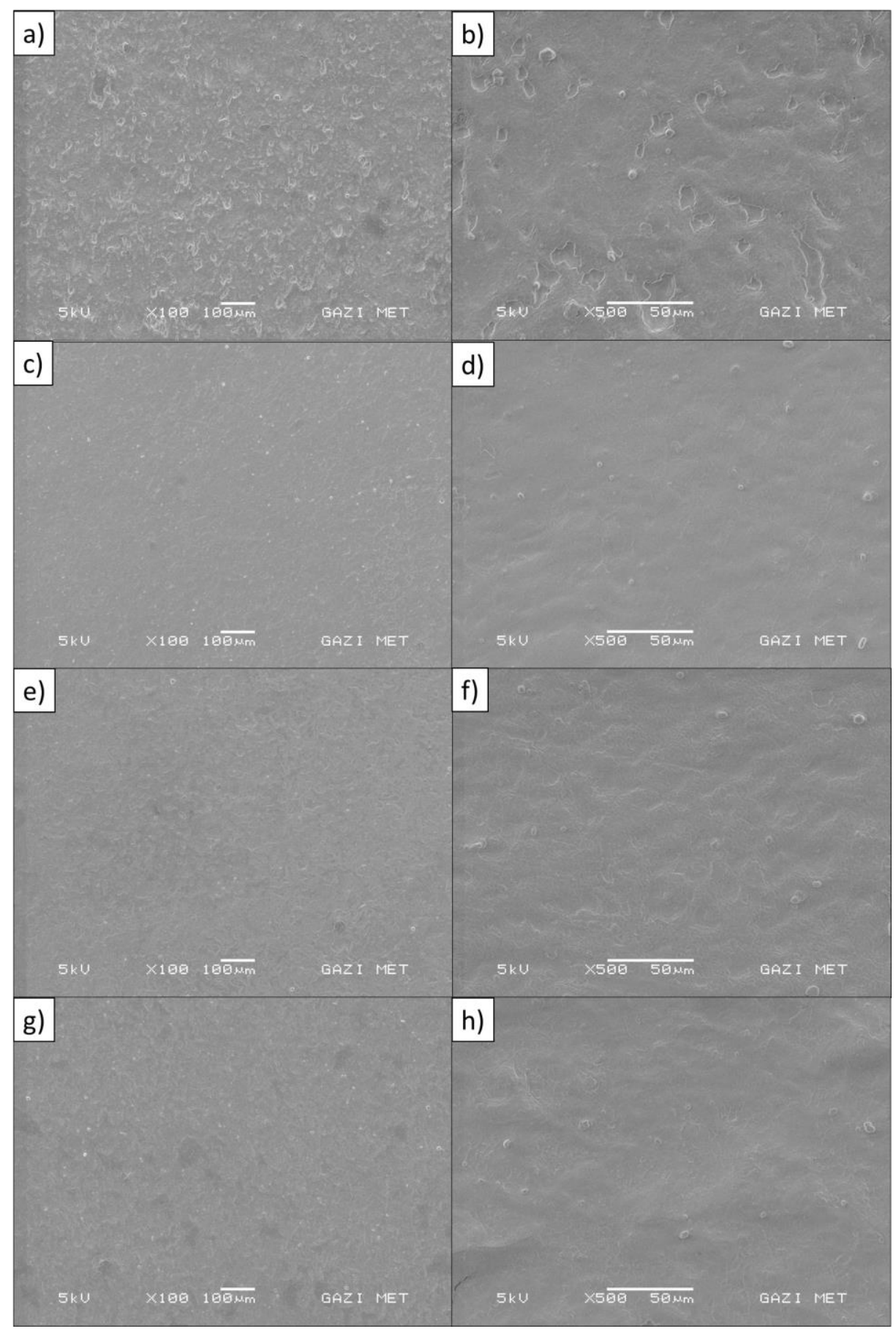

Şekil 3. a,b) 25 , c,d) 45 , e,f) 65 ve g,h) $85^{\circ} \mathrm{C}$ sıcaklıklarda asit aşındırma işleminden sonra kaplanan numune yüzeylerine ait SEM görüntüleri (100X ve 500X).

Şekil 4'te farklı sıcaklıklardaki yüzey aşındırma işlemi sonrası elde edilen kaplamaların kesitten alınan SEM görüntüleri ve kaplama kalınlıkları mevcuttur. Kaplama kalınlıklarının tüm numunelerde homojen ve 2,52 $\pm 0,02 \mu \mathrm{m}$ olarak ölçülmesi asit işlem sıcaklığının yüzeyde biriktirilen malzeme miktarını etkilemediğini göstermektedir. Şekil 5 ise $25{ }^{\circ} \mathrm{C}$ 'de işlem görmüş ve tantal oksit kaplanmış 
numune yüzeyinden alınan genel EDS analizini göstermektedir. Alınan EDS analizinde altlığa ait elemente rastlanmaması kaplamanın tüm yüzeyde elde edilebildiğini ve altlık malzemenin tamamen izole edilebildiğini göstermektedir.

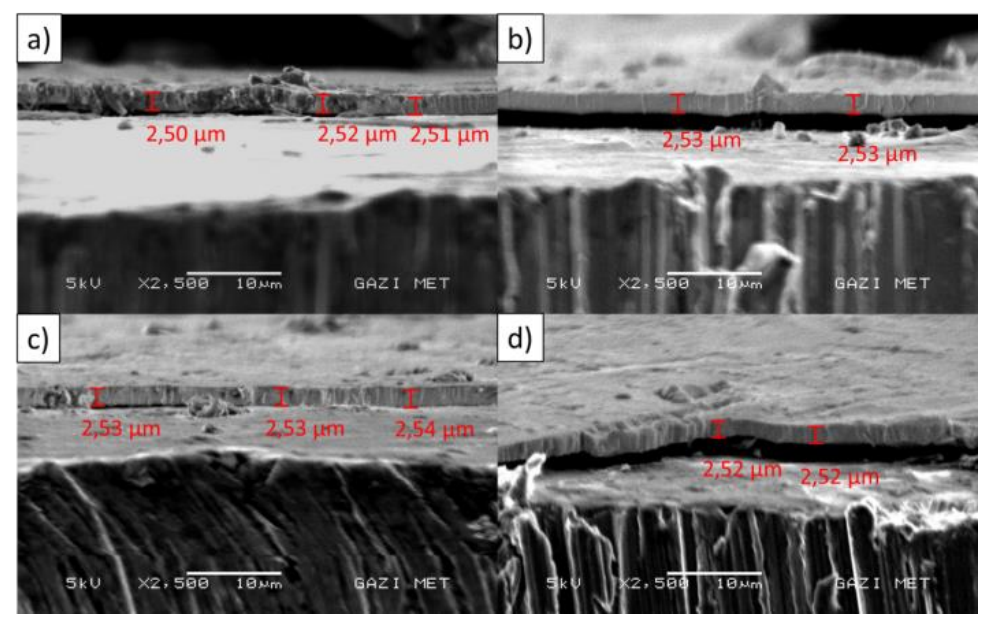

Şekil 4. a) 25 , b) 45 , c) 65 ve d) $85^{\circ} \mathrm{C}$ sıcaklıklarda aşındırıldıktan sonra kaplanan numunelerin kesitten alınan SEM görüntüleri ve kaplama kalınlıkları.

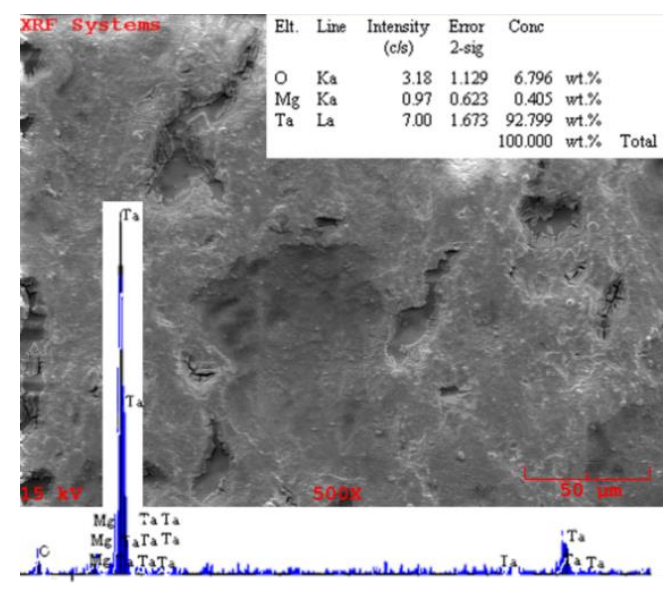

Şekil 5. Kaplanmış yüzeyden alınan genel EDS spektrumu $\left(25^{\circ} \mathrm{C}\right)$

45-65-85 ${ }^{\circ} \mathrm{C}^{\prime}$ de asit işlemi sonrası kaplanan numunelerin kesitlerinden alınan SEM görüntüleri ve bu SEM görüntüleri üzerinde görülen kaplama ve altlık malzemeden alınan EDS'lere ait analiz sonuçları Tablo 1'de verilmiştir. Özellikle bakalite alınarak hazırlanmış olan bu kesit görüntülerinden altlık ve malzeme ara yüzeyinin birbirine iyi tutunduğu arada boşlukların veya kaplanmayan bölgelerin bulunmadığı net bir şekilde görülmektedir. Yine Tablo 1'de verilen EDS analizleri, Şekil 5'teki EDS analizine yakın sonuçlar göstermekte ve birbirini destekler niteliktedir.

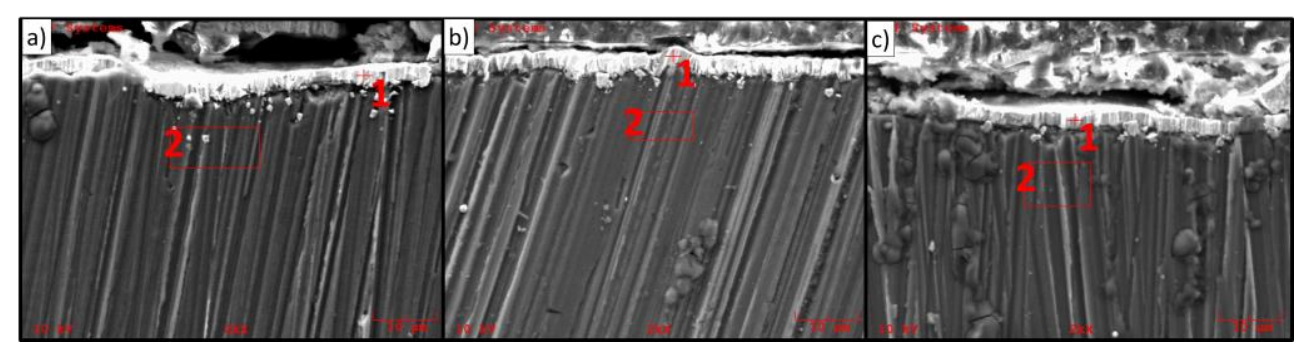

Şekil 6. a) 45 , b) 65 , c) $85^{\circ} \mathrm{C}$ sıcaklıklarda aşındırıldıktan sonra kaplanan numunelerin kesit kaplama görüntülerinden alınan SEMEDS görüntüleri. 
Tablo 1. $45-65-85^{\circ} \mathrm{C}$ 'de asit işlemi sonrası kaplanan numunelerin EDS analiz sonuçları.

\begin{tabular}{lccll}
\hline & Mg (ăg. \%) & Zr (ağ. \%) & O (ağ. \%) & Ta (ă̆. \%) \\
\hline $45-1$ & 0,006 & 0,002 & 0,069 & 99,923 \\
$45-2$ & 97,893 & 0,804 & 1,302 & 0,000 \\
$65-1$ & 0,003 & 0,184 & 1,088 & 99,977 \\
$65-2$ & 96,792 & 1,848 & 1,360 & 0,000 \\
$85-1$ & 0,005 & 0,000 & 0,077 & 99,918 \\
$85-2$ & 96,768 & 1,404 & 1,027 & 0,000 \\
\hline
\end{tabular}

XRD analizleri sonucunda elde edilen desenler Şekil verilmiş olup Mg alaşımında fazlaca bulunan $\alpha$-Mg fazına ait pikler elde edilmiştir. Pikler EvaDiffrac kütüphanesi aracıllğ̆ ile eşleştirilmiştir. WE43 numunelerde ana faz $\alpha$-Mg'dur. XRD desenine ait pikler Pereira vd., (2021) ve Dvorsky vd., (2020) çalışmalarında verilen WE43 alaşımına ait piklerile uyumludur (Pereira vd., 2021; Dvorsky vd., 2020).

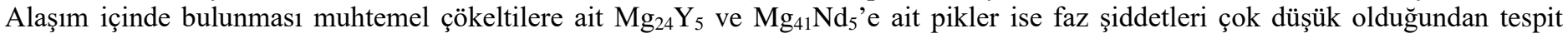
edilememiştir. Aynı durumun Dvorsky vd., (2020) yaptıkları çalışmada da söz konusu olduğunu ve bunun nedeni olarak düşük şiddetli olmasına atfedilmiştir (Dvorsky vd., 2020).

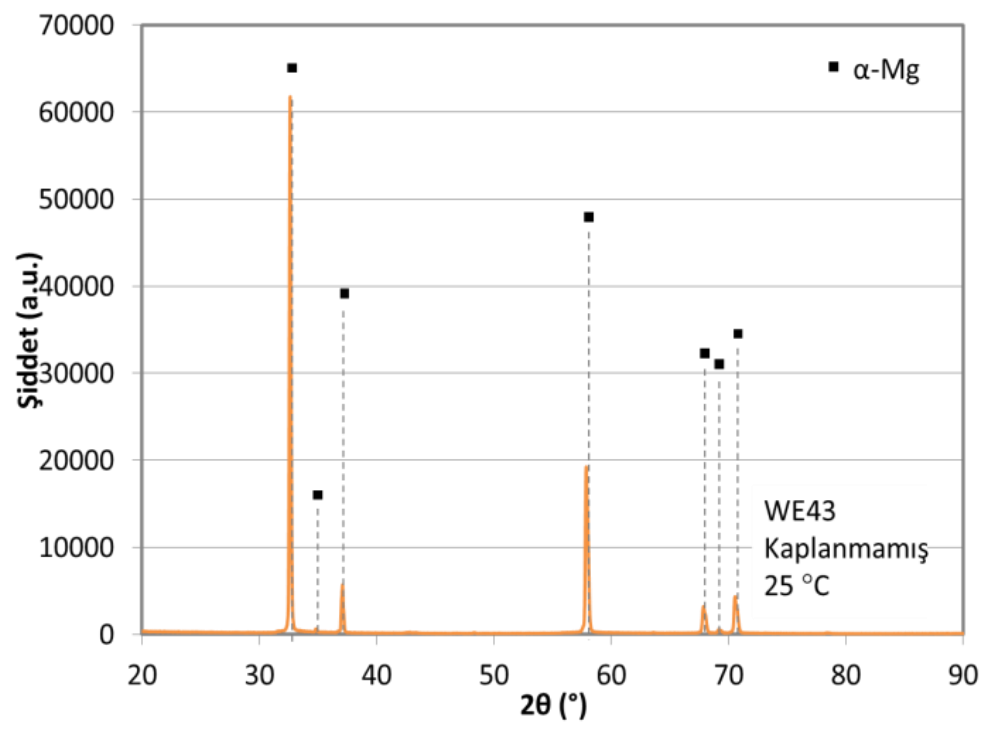

Şekil 7. Kaplanmamış $25^{\circ} \mathrm{C}$ de asit ile aşındırılmış WE43 alaşımına ait XRD grafiği.

Şekil 8'de ise kaplanmış numunelere ait XRD grafiği verilmiştir. Grafikteki eğriler incelendiğinde pik şiddetlerinde bir değişim olmadığ herhangi bir faz tespit edilmediği düşünülmüştür. Kaplanmamış numuneye ait XRD grafiği ile kaplanmış numunelere ait grafikler kıyaslandığında; kaplanmış numunelerde, amorf numunelerde karakteristik olarak gözlemlenen yapı gözlemlenmeye başladığı tespit edilmiştir. Altlık Mg alaşımından gelen pikler nedeni ile kristal bir yapı tespit edilebilmiş olsa da bu durumda kaplamaların amorf yapıda olduğu söylenebilir. Tantal-oksit $400{ }^{\circ} \mathrm{C}$ sıcaklıkta amorf yapıda gözlemlenmekte olup Bansal vd. (1993), yaptıkları çalışmada tantal-oksitin faz geçiş sıcaklıklarını tespit etmiş ve bahsedilen sıcaklıklarda amorf aralıkta olduğunu göstermiştir (Bansal vd., 1993). 


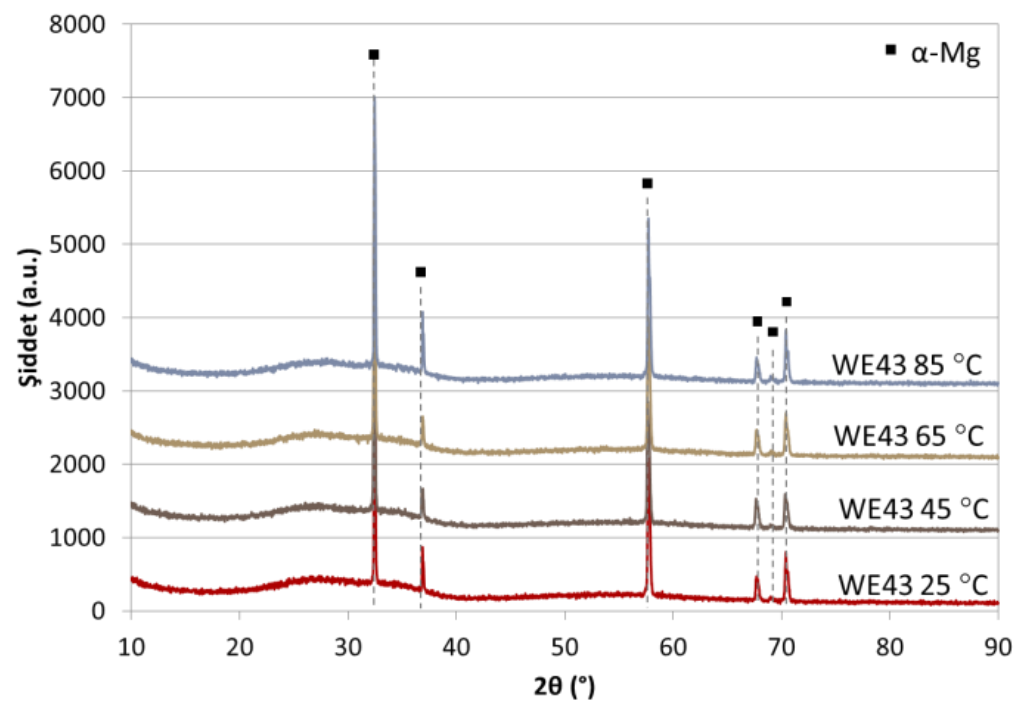

Şekil 8. $25,45,65$ ve $85^{\circ} \mathrm{C}$ sıcaklıklarda aşındırıldıktan sonra kaplanan numunelere ait XRD grafiği.

\section{Sonuç}

Yapılan bu çalışma ile ekstrüze halde alınan WE43 Mg alaşım numunelerin yüzeyleri, 25, 45, 65 ve $85^{\circ} \mathrm{C}$ sıcaklıklarda asit ile muamele edilerek, RF sıçratma yöntemi vasıtasıyla tantal oksit kaplanmışıtır. Uygulanan farklı sıcaklıktaki asit modifikasyonlarının kaplanmış numune morfolojilerine olan etkileri incelenmiş̧ir.

Çalışma sonucunda, yüzeylerde 2,52 $\pm 0,02 \mu \mathrm{m}$ kalınlıkta kaplamalar elde edilmiştir. Kaplamalar çatlaksız, boşluksuz ve homojen bir şekilde elde edilebilmiş olup SEM-EDS incelemeleri ile yapılan kaplamalar doğrulanmıştır. Kaplamalar amorf yapıda malzeme yüzeylerinde elde edilmiş ve uygulanan asit aşındırma işlemleri kaplama kalınlığını etkilemeksizin yüzeyde herhangi bir farklı faz oluşumuna neden olmamışırır.

\section{Referanslar}

Almeida, E. (2001). Surface Treatments and Coatings for Metals. A General Overview, Surface Treatments, Surface Preparation, and the Nature of Coatings. Industrial \& Engineering Chemistry Research, 40(1), 3-14.

Antion, C., Donnadieu, P. \& Perrard, F. (2003). Hardening precipitation in a Mg-4Y-3RE alloy. Acta Materialia, 51, 5335-5348.

Bansal, N. P. (1993). Low Temperature Synthesis of Monolithic Transparent Ta205 Gels From Hydrolysis of Metal Alkoxide. NASA Technical Memorandum, 106246.

Byun, S.-H., Lim, H.-K., Cheon, K.-H., Lee, S.-M., Kim, H.-E. \& Lee, J.-H. (2020). Biodegradable magnesium alloy (WE43) in bonefixation plateand screw. Journal of Biomedical Materials Research: Part B Applied Biomaterials, 108B, 2505-2512.

Cao, G., Zhang, D., Zhang, W. \& Zhang, W. (2016). In Vitro Corrosion Study of Friction Stir ProcessedWE43 Magnesium Alloy in a Simulated Body Fluid. Materials, 9, 542.

Chang, Y.-Y., Huang, H.-L., Chen, H.-J., Lai, C.-H., and Wen, C.-Y. (2014). Antibacterial properties and cytocompatibility of tantalum oxide coatings. Surface and Coatings Technology, 259(B) 193-198.

Chen, X., Bai, R., \& Huang, M. (2019). Optical properties of amorphous $\mathrm{Ta}_{2} \mathrm{O}_{5}$ thin films deposited by RF magnetron sputtering. Optical Materials, 97, 109404.

Dvorsky, D., Kubasek, J., Jablonska, E., Kaufmanova, J. \& Vojtech, D. (2020). Mechanical, corrosion and biological properties of advanced biodegradable $\mathrm{Mg}-\mathrm{MgF}_{2}$ and $\mathrm{WE} 43-\mathrm{MgF}_{2}$ composite materials prepared by spark plasma sintering. Journal of Alloys and Compounds, 825, 154016. 
Gül, C., Albayrak, S., \& Çinici, H. (2020). Characterization of Tantalum Oxide Sol-Gel-coated AZ91 Mg Alloys. Transactions of the Indian Institute of Metals, 73 (5), 1249-1256.

Gül, C. \& Albayrak, S. (2021). WE43 Magnezyum Alaşımlarında Yüzey Modifikasyonlarının Morfolojik Özelliklere Etkisi. C. Yücelbaş (Ed.), Mühendislikte Konstrüksiyon, İmalat ve Malzeme Üzerine Güncel Araştırmalar içinde(27-40). Ankara: İksad Yayınevi.

Hänzi, A. C., Gunde, P., Schinhammer, M. \& Uggowitzer, P. J. (2009). On the biodegradation performance of an Mg-Y-RE alloy with various surface conditions in simulated body fluid. Acta Biomaterialia, 5(1), 162-171.

Höhlinger, M., Heise, S., Wagener, V., Boccaccini, A. R. \& Virtanen, S. (2017). Developing surface pre-treatments for electrophoretic deposition of biofunctional chitosan-bioactive glass coatings on a WE43 magnesium alloy. Applied Surface Science, 405, 441-448.

Ignat, S., Sallamand, P., Grevey, D. \& Lambertin, M. (2004). Magnesium alloys laser (Nd:YAG) cladding and alloying with side injection of aluminium powder. Applied Surface Science, 225(1-4), 124-134.

Kubásek, J., Dvorský, D., Čavojský, M., Roudnická, M. \& Vojtech, D. (2019). WE43 magnesium alloy - material for challenging applications. Kovove Materialy-Metallic Materials, 57 (3), 159-165.

Pereira, G.S., Koga, G.Y., Avila, J.A., Bittencort, I.M., Fernandez, F., Miyazaki, M.H., Botta, W.J. \& Bose Filho, W.W. (2021). Corrosion resistance of WE43 Mg alloy in sodium chloride solution. Materials Chemistry and Physics, 272, 124930.

Yang, C., Gupta, N., Ding, H. \& Xiang, C. (2020). Effect of Microstructure on Corrosion Behavior of WE43 Magnesium Alloy in As Cast and Heat-Treated Conditions. Metals, 10, 1552.

Zucchi, F., Grassi, V., Frignani, A., Monticelli, C. \& Trabanelli, G. (2006). Influence of a silane treatment on the corrosion resistance of a WE43 magnesium alloy. Surface and Coatings Technology, 200, 4136-4143. 